M. Falret is due the first emphatic account of folie circulaire; but Willis, in 1680, speaking of mania and melancholia, says, "Hi affectus sape viecs conmutent, ot alteruter in alterutrum transeat." I cannot vicw these cases as belonging to, or constituting, a separate form of diseuse. 'The fact is, that in chronic insanity very frequent alternations of the piotient's state cccurs, and every variety of alternation is found. Sometimes the patient is restless one week and dull at another period; or the same talies place on alternate days, or montus; or one may gro even several months, and then have a period of decicled maniacal excitement; incleed, among a number of chronic lunatics, such is the rille rather than the exception. Very few chronic lunatics, before they sink into absolute imbecility, wre free from occasional outbreaks of excitement; and many have periors of depression, also; and, on the other hand, many who have sunk into absolute dementia are also at times excited and violent. Out of the large number of chronic jaticnts, an infinite variety in tie mocies of alternations must be found; and, in a small proportion, this somewhat regular interchange of lowness and excitement occurs. The condition is always allied to a state of imbecility, and, like all disease in a chronic state, is rery incurable.

With respect to tho states of imbecility and dementia, all degrees of mental debility are to be met with. On the subsidence of the acute stage, some patients, of course, regain perfect sanity of mind; in others, on the subsidence of the morbid process, a permanent mental defect remains. The patient recovers, like one from a fractured leg, with a permanent limp or halt. It is to certain cases of this description, that English writers apply the term monomania. The Frenci, however, use that term for chronic insanity, or chronic mania. A condition of monomania, or of a mental defect on one point, as the term is used in England, is an absurdity, if the definition is to be applied with scientific strictness. Every mental operation is more or less complex; indeed, the simplest proposition involves many mental faculties. For example, when a patient believes himself to be king, how many mental actions aro brought into play, as judgment, reason, memory, etc. ?

Many states of mind, however, are met with on the subsidence of active disease. There is this peculiarity about them, which marks their chronic character-they are connected with the intellect proper. They are crrors chiefly of judgment, reason, associatron of idcas, etc.; and involve to a much less degree or more indirectly the moral attributes of mind. 'The condition is a stage of chronic disease; it may be permanent or nearly so, or transitional to a greater degree of mental debility; and whether we call the state monomania, or chronic mania, or chronic insanity, it is still but a stage of one original or primary disease, which may have occurred with predominating maniacal or melancholic symptoms.

When a persistent false belicf-that is, a delusion -is found, the case in which it occurs is chronic and of long standing. A delusion, an alteration of the intellect, does not occur in the first stage of the dis. case. At least, such is my experience. I have received patients who have had a particular and predominating delusion, whose cases have been certitied to be perfectly recent, and the symptoms to be primary; but which have all proved to be otherwise on a more careful investigation.

Many of these cases appear to be stationary ; certainly many continue in one state for years; yet, in all, there is a gradual declining of the mental power. In some, the progress is rapid and evident ; in other's, slower and almost iupercentible. In by fur the lurger portion, a state of imbecility and dementia gradually becomes established.

When the diseaso has advanced to this stage, recovery is of course hopeless. However, as the mind becomes more and more feeble, the patient may be, by careful attention, re-instructed in many matters, and habits lost in the acute stare of disease can be restored. Very many, eren of the worst cases-even those who have lost all ideas of propricty or decency of behaviour-have been rendered orderly, quiet, and cleanly, by good nursing. Indeed, taking the class as a whole, perhaps there is none for which amelioration of the condition cun be so safely promised as for the imbecile and demented.

To the Commissioners in Lunacy, and to $\mathrm{Mr}$. Gaskell especially, is duc the attention which the specialty have lately given to this branch of treatment. At Ilanwell, the number of wet and dirty patients was reduced from 10 per cent. to 2 per cent. by careful attention day and night; and with the cure of wet and dirty habits, there was a corresponding improvement in habits of propriety and decency, as well as in health and comfort. By the word cure is meant that the habit was eradicated. Many patients who required to be roused twice or eren three times during the night at first, afterwards required attention once only, and at length no attention at all, and were restored to the wards appropriated for the cleanly or orderly classes.

[To be continued.]

\section{A CASE OF CHOREA.}

By John Thompson, M.D., F.R.C.S., Bideford.

THE article in a late number of the Journac by Dr. J. Turnbull, on chorea, has brought forward a subject, on which much has been written, and yet no very precise information rendered respecting the pathology or the treatment of the disease, on both which our knowledge is painfully defective.

A well written description, such as the one referred to, embraces the general characters of the disease, and points out graphically striking fucts; as that rheumatism and chorea have sometimes a clear relationship; also that chorea and bysteria sometimes approximute closely. But, nevertheless, a number of phenomena are still undescribed, which yet appear to belong to chorea in some one of its forms, as I think the following case will show.

I was consulted in February 1864 for a well grown intelligent girl of fourteen, under the following circumstances. She had menstruated regularly for some time, but the quantity was in excess; and she was weak, apparently from this cause. There was pain in the right elbow-joint, which contained a little effusion; and this condition impaired the mobility. In other respects, there seemed not much the matter. The joint-affection was believed to be rheumatic; and this was confirmed by a speedy accession of the same character of pain about the intercostals of the left side. The stomach became very irritable; food was seldom retained; the bowels were rather constipated; menstruation ceased. The spine was sensitive along the whole line of the spinous processes; and some disposition to twitching was occasionally manifested about the neck and extremities. There came on a peculiar convulsive voice-sound, somewhat resembling hiccough, repeated with almost the rapidity of time-seconds, and accompanied with an agritation of the neck much resembling paralysis agitans. All these had been developed by the beginning of April. At that time $D_{1}$. Brown, of this place, met me in consultation; her case bcing then, in brief, as follows. 
Vomiting almost always follows any taking of food. The bowels are rather constipated. 'There is a constant tremulous movement of the head and neck, and the peculiar laryngeal sound before described. The limbs are rather tremulous on being used; and there appears to be anchylosis of the diseased clbow-joint. She cannot stand, nor sit up without being supported. The agitation of her system and the voicesound entirely subside on her taking sleep.

I had already given her steel, effervescing salines, iodide of potassium, calumba, opium, etc.; some of these being directed to the improvement of the tone of the system, others to the relief of the vomiting. Some counterirritation was employed over the spine, to the side, and to the elbow; and every attention given to the diet, ventilation of the room, and nursing.

During another month, we tried the preparations of zinc, the mineral acids, strychnia, cod-liver oil, occasional doses of purging medicine, with a little blue pill; and supported her strength in every possible way. Counterirritation was still applied to the opine.

The case did not at all seem benefited by our assiduity; and we now recommended her to be taken to a house in the country, in a commanding situation, and enjoying a strong breeze from the Atlantic. When sle left, she still hall the agitation of the voluntary muscles, and the spasmodic action of the larynx ; and both these were notably increased if she were humied by the intrusion of a stranger, or by any undue notice of her ailment. After being in the country for some weeks, the agitation of the neck (which was continuous when she left), as also the voice-sound, ceased; but the irritability of the stomach was in no way abated.

It was now detemined to omit the medicines, and see what would bo the effect of trusting to the influence of the country air; counterirritation by means of mustard being still advised as an occasional application. The omission of the medicine was attended with no improvement in the symptons, the romitins being even worse than before, and the patient could not be induced to take any food. I cndeavoured to support her system by means of injections of good broth or milk, and these were continued for some weeks. During this period, vomiting sometimes occurred; and blood was occasionally ejected in some quantity.

At length the patient objected so strongly to the use of tiie injections, that they were first omitted occasionally, ancl at length discontinued, in spite of my advice to the contrary. I warned the friends that, without fool, it was impossible that life could long be sustained; but to no purpose. The patient was inflexille, and they would not consent that force should be employed. But, notwithstanding the abstinence fiom food and drink, the patient lived on. An injection of water was twice used to unload the bowels; but no other interference with nature took place.

A most complete abandonment of the case was made; fir I believed that the craving from hunger would compel the patient in no long time to eat; but in this I have been entirely disuppointed, for she has now bee: over six months without having taken a morsel $a^{\circ}$ food or moistened her mouth with fluid, so far ats is known. She has had no injection for serevial months; the bowels do not act, nor is any water pisscd. H.er condition resembles that of hybernation; rolled up in a little bed in the corner of a room, she takes no notice of any one, and only nnswers in a low whisper any question that is put to her.

Her pulse is now about 120 in the minute, and the respirations about 16. The breathing during the ill- ness has been generally slow, and the pulse much less frequent than at present.

At times she has becn in a state of great excite- ment; has had croupy breathing; and a disposition $\frac{\partial}{\sigma}$ to hysterical convulsion, throwing about her hands, and endeavouring to pluck out her hair. It has been $\frac{\omega}{\vec{T}}$ necessary for her attendant to restrain her for an $\mathbb{Q}$ hour or two at a time, when this has occurred. For the last few montlis, nature has seemed too much ex- $\infty$ hausted to allow such exertion.

It is now over ten months, since this patient came under my attention. She took very little food for the $\vec{\omega}$ first four months, and is believed to have taken none $\omega$ for the last six. The residence in the country, which $\bar{O}$ extended over four months, benefited her, in that 3 . all the paralytic agitation and spasms were removed; - . but no improvement took place in any other respect. The last time an evacuation was procured, the matter $\vec{G}$ was scybalous, and strung bead-like; the last evacu- $\vec{c}$ ations of urine resembled the thick ammoniacal fluid, $\vec{v}$ which coustitutes the urine in birds.

She is greatly emaciated; her spine being parti.을 cularly distinct, and every bone in it defined. There is tenderness over the spines; but no paralysis in any part of the body. The surface of her skin is now, $T$ and has bcen throughout her illness, rather cold; thəo음 superficial blood-vessels appear congested; the extremities are not œdematous.

The facts of this, which I deem a most extraor-dinary case, will probably be received by some witho a feeling of scepticism. On my part, I shall be happyor to give any further explanation of the statements $I^{\prime}$ have made, either by private communication oro through the pages of the JourNar.

\section{$\checkmark$}

\section{RETROSPECTIVE NOTES ON OUT- PATIENT PRAC'TICL.}

By C. M. Durrant, M.D., Physician to the East Suflolk and Ipswich Hospital.

\section{Diaestive Sratem. (Continued from p. 114.)}

\section{Congestion of the Liver. The affection classed} under this head might, it may be thought, have been included in one of the varieties of dyspepsia. The symptoms, however, pertaining to hyperæmia, or abs normal accumulation of blood in the capillaries of the liver, differ sufficiently from those of simple dyspepsia to merit and call for a separate notice. Congestion of the liver is a prelude to almost all diseases of the organ terminating in alteration of structure; but, in the cases to which these notes have reference, the affection depended solely upon simple engorgemento of the hepatic circulation, and were quite distinces from the passive congestion and enlargement arising: from cardiac or other organic visceral diseases. $N$ Patients with this affection generally present dusky, semi-jaundiced hue. The tongue has a thin yellowisi coating. There are nausea and more oश less anorexia, although at the commencement the appetite is somctimes ravenous. The chief complaint is of a dull heavy pain in the right hypochondriumo On examining this region, the natural hepatic dul? ness is increased; and pain is caused by pressing the्ण liver upwards from the costal margin, where wo mas not uufrequentiy detect the enlarged and turgid edge of the organ itself. The bowels are for the most par confined, and the excretions dark, offensive, and bilious; and complaint is often made of pain in defar cation, from enlarged and swollen limorihoidad veins. The urine is scanty and high coloured; and in some cases the nervous system sympathises, evidenced by great mental depression, together wite
tingling and numbness of the extremities. 